\title{
Oferta das Graduações em Medicina e em Enfermagem no Brasil
}

\author{
Formation in Medicine and Nursing in Brazil
}

\section{PALAVRAS-CHAVE:}

- Recursos Humanos em Saúde;

- Escolas Medicas;

- Bacharelato em Enfermagem.

\section{KEY-WORDS:}

- Health Manpower;

- Schools, Medical ;

- Education, Nursing, Baccalaureate.

Recebido em: 03/01/2006

Reencaminhado em: 06/07/2006 Reencaminhado em: 17/10/2006 Aprovado em: 27/10/2006

\footnotetext{
${ }^{1}$ Escola Nacional de Saúde Pública Sergio Arouca, Fiocruz, Rio de Janeiro, Brasil.

${ }^{2}$ Escola Nacional de Saúde Pública Sergio Arouca, Fiocruz, Rio de Janeiro, Brasil.

Instituto de Medicina Social, Escola Nacional de Saúde Pública Sergio Arouca, Fiocruz, Rio de Janeiro, Brasil.
}

Antenor Amâncio Filho ${ }^{1}$ Ana Luiza Stiebler Vieira ${ }^{2}$ Ana Claudia Pinheiro Garcia ${ }^{3}$

Este trabalho enfoca o sistema educativo das graduações em Medicina e Enfermagem, considerando o período de 1995 a 2003. Apresenta as principais características dessas graduações no Brasil - oferta de cursos, de vagas e quantidade de egressos segundo dependência administrativa das instituições (pública, privada) e sua distribuição geográfica -, a partir de dados fornecidos pelo Instituto Nacional de Estudos e Pesquisas Educacionais Anísio Teixeira (Inep), do Ministério da Educação. Os resultados obtidos assinalam distorções na distribuição da oferta dessas graduações, podendo servir como subsídios para as instâncias gestoras do Sistema Único de Saúde na formulação e implementação de uma política de recursos humanos condizente com os princípios e diretrizes desse sistema, direcionada à formação de profissionais competentes tecnicamente e comprometidos com a resolução das demandas e necessidades de saúde da população.

\begin{abstract}
The present study focuses the medicine and nursing graduation system, considering the period 1995 - 2003. It presents the main characteristics of these graduations in Brazil - offer of courses, vacancies and amount of egresses according to the administrative dependence of the institutions (public, private) and their geographic distribution - based on data provided by the National Institute of Studies and Educational Research Anísio Teixeira (Inep) of the Ministry of Education. The results obtained in this study point to distortions in the configuration of these graduations and can aid the managing authorities of the Brazilian Unified Health System (SUS) in the formulation and implementation of a human resources policy consistent with the principles and guidelines of the system and engaged in graduating not only technically competent professionals but professionals committed to the solution of the health demands and needs of the population.
\end{abstract}




\section{INTRODUÇÃO}

A formação de recursos humanos para a saúde é um importante tema e uma crucial questão em busca de equacionamento que, há longo tempo, vem preocupando educadores, pesquisadores, planejadores e formuladores de políticas públicas para a área. As dificuldades enfrentadas nesse terreno podem ser mais bem compreendidas quando se pensa que a formação desses profissionais, consideradas as diferentes categorias que o campo da saúde abarca, envolve um conjunto de variáveis que permitem aliar o domínio da técnica à capacidade de agir politicamente, com os objetivos de garantir e fortalecer os princípios e diretrizes que regem o Sistema Único de Saúde. Ademais, a construção do SUS envolve situações e possibilidades novas, ao exigir estratégias de ação que tenham como referência os princípios éticos da universalidade, da eqüidade e da integralidade, visando garantir à população o acesso igualitário aos serviços de promoção, proteção e recuperação da saúde.

Nesse contexto, é amplo o elenco de questões que merecem ser analisadas com coragem, sensatez e acuidade, entre elas a (re)organização da oferta de serviços de saúde com base nas necessidades da população, a manutenção e o cumprimento da legislação que prevê e garante as fontes orçamentárias para a saúde, as formas de gestão do trabalho e de regulação das profissões, o implemento da responsabilidade sanitária, sob a ótica de um pacto federativo assentado na descentralização e na regionalização das ações da saúde.

Formar recursos humanos para a saúde representa, em especial, firmar uma estreita e articulada parceria entre as áreas da educação e da saúde, aliadas à de ciência, tecnologia e inovação em saúde, dando corpo a um movimento que afirme ser necessário romper com a prática de políticas setoriais independentes. Levando em conta "a relação entre educação e trabalho, a mudança na formação e produção de conhecimento e a recomposição das práticas de atenção, gestão, ensino e controle social no setor saúde" ${ }^{\prime 1}$, essa agenda intersetorial é medida estratégica para favorecer o intercâmbio entre os serviços de saúde, as instituições formadoras e as de ciência e tecnologia, para a consecução compartilhada de atividades de ensino, pesquisa e extensão nos diversos níveis de atenção à saúde da população.

Assim, a formação e o desenvolvimento de recursos humanos se apresentam como um desafio a vencer para que se alcancem os objetivos propostos pela política nacional de saúde. É um processo complexo, que envolve mudanças conceituais, de postura e de relações institucionais, e que inclui o enfrentamento de saberes e de valores hegemônicos, sedimentados tanto nas instituições de ensino que formam para o setor, quanto nas organizações que respondem pelos serviços de saúde.
Não é incomum, portanto, que as reformas curriculares pretendidas ou praticadas na esfera da formação para a saúde encontrem resistências e acabem por se limitar a mudanças na nomenclatura de disciplinas ou na reinvenção de métodos e técnicas pedagógicas, mantendo-se intactas as representações acerca do trabalho em saúde. A existência de dispositivo constitucional que estabelece para a saúde a responsabilidade pelo ordenamento da formação de seus recursos humanos não significa nem é garantia de que o setor, de maneira isolada, possa cumprir essa missão, que inclui a formação, a gestão de pessoal, os programas de educação permanente, a regulação do exercício profissional.

Para a elaboração do presente documento, foram analisados dados fornecidos pelo Instituto Nacional de Estudos e Pesquisas Educacionais Anísio Teixeira (Inep), do Ministério da Educação, relacionados a cursos, vagas e egressos segundo dependência administrativa e unidade federada, no período de 1995 a 2003, relativos a Medicina e Enfermagem, duas das 14 graduações pertencentes ao campo da saúde, de acordo com o Conselho Nacional de Saúde. Fez-se uma análise de eventuais duplicidades de registro e uma uniformização dos nomes dos cursos de graduação das duas profissões, tendo sido geradas tabelas, planilhas e gráficos para cada uma das profissões objeto do estudo.

Este artigo contribui para o debate sobre o assunto, visando a mudanças nos meios e modos adotados para a formação e o desenvolvimento de recursos humanos, de maneira que sua implementação aconteça sob os marcos dos direitos sociais e da atenção integral à saúde, objetivando o fortalecimento do Sistema Único de Saúde.

\section{DINÂMICA DAS GRADUAÇÕES EM MEDICINA}

\section{Crescimento da oferta em Medicina}

No período analisado, os cursos de graduação em Medicina cresceram 47,0\%, ou seja, da oferta de 85 cursos em 1995 , para 125 em 2003 (Tabela 1). Este aumento é observado a partir de 1997 e, mais acentuadamente, nos anos 2000. O total de vagas acompanha o aumento dos cursos, passando de 8.247 para 12.081 vagas, significando um crescimento de $46,5 \%$. A repercussão da oferta de profissionais médicos começa a ser observada a partir de 2001, em decorrência do aumento dos cursos na década de 1990. Se até 2000 a média anual de egressos se manteve estável (em torno de 7.600 graduados), nos anos subseqüentes eleva-se para 8.500 concluintes. Verifica-se que a oferta de 7.622 novos profissionais em 1995 passa para 9.113 em 2003, representando um aumento de 19,6\%, índice que deverá ser ampliado nos próximos anos, em função do tempo exigido para a formação. 
A comparação da evolução do número de vagas ofertadas com o número de egressos - considerando-se o quantitativo de egressos do ano de 2001 (8.004) e o de vagas de 1995
(8.347), assim como estes correspondentes números em 2003 (9.113 egressos) e 1997 (9.001 vagas) - sugere baixa evasão para os cursos de Medicina.

TABELA 1

Cursos, vagas e egressos da graduação em Medicina por regiões, segundo unidades federadas. Brasil, 1995 e 2003

\begin{tabular}{|c|c|c|c|c|c|c|}
\hline \multirow{3}{*}{$\begin{array}{l}\text { Graduação } \\
\text { Região/UF }\end{array}$} & \multicolumn{6}{|c|}{ Medicina } \\
\hline & \multicolumn{2}{|c|}{ Cursos } & \multicolumn{2}{|c|}{ Vagas } & \multicolumn{2}{|c|}{ Egressos } \\
\hline & 1995 & 2003 & 1995 & 2003 & 1995 & 2003 \\
\hline Brasil & 85 & 125 & 8.247 & 12.081 & 7.622 & 9.113 \\
\hline Norte & 4 & 10 & 360 & 872 & 319 & 369 \\
\hline Acre & 0 & 1 & 0 & 40 & 0 & 0 \\
\hline Amapá & 1 & 0 & 80 & 0 & 75 & 0 \\
\hline Amazonas & 0 & 3 & 0 & 332 & 0 & 76 \\
\hline Pará & 2 & 2 & 250 & 250 & 244 & 262 \\
\hline Rondônia & 0 & 1 & 0 & 40 & 0 & 0 \\
\hline Roraima & 1 & 1 & 30 & 20 & 0 & 31 \\
\hline Tocantins & 0 & 2 & 0 & 190 & 0 & 0 \\
\hline Nordeste & 14 & 21 & 1.574 & 1.802 & 1.281 & 1.456 \\
\hline Alagoas & 2 & 2 & 150 & 130 & 128 & 135 \\
\hline Bahia & 2 & 4 & 560 & 430 & 310 & 359 \\
\hline Ceará & 1 & 5 & 140 & 370 & 136 & 158 \\
\hline Maranhão & 1 & 2 & 70 & 122 & 121 & 79 \\
\hline Paraíba & 2 & 2 & 164 & 180 & 158 & 180 \\
\hline Pernambuco & 3 & 2 & 290 & 290 & 219 & 294 \\
\hline Piauí & 1 & 2 & 50 & 110 & 52 & 76 \\
\hline Rio Grande do Norte & 1 & 1 & 80 & 90 & 83 & 94 \\
\hline Sergipe & 1 & 1 & 70 & 80 & 74 & 81 \\
\hline Sudeste & 46 & 60 & 4.757 & 6.748 & 4.550 & 5.546 \\
\hline Espírito Santo & 2 & 2 & 200 & 200 & 216 & 228 \\
\hline Minas Gerais & 10 & 16 & 1054 & 1606 & 1039 & 1099 \\
\hline Rio de Janeiro & 15 & 17 & 1930 & 2400 & 1700 & 2127 \\
\hline São Paulo & 19 & 25 & 1573 & 2542 & 1595 & 2092 \\
\hline Sul & 17 & 24 & 1.298 & 1.927 & 1.222 & 1.408 \\
\hline Paraná & 5 & 7 & 406 & 626 & 395 & 445 \\
\hline Rio Grande do Sul & 10 & 11 & 752 & 888 & 729 & 794 \\
\hline Santa Catarina & 2 & 6 & 140 & 413 & 98 & 169 \\
\hline Centro-Oeste & 4 & 10 & 258 & 732 & 250 & 334 \\
\hline Distrito Federal & 1 & 4 & 60 & 312 & 46 & 69 \\
\hline Goiás & 1 & 1 & 110 & 110 & 105 & 108 \\
\hline Mato Grosso & 1 & 2 & 40 & 140 & 44 & 105 \\
\hline Mato Grosso do Sul & 1 & 3 & 48 & 170 & 55 & 52 \\
\hline
\end{tabular}

Fonte: Inep/MEC. 


\section{DISTRIBUIÇÃO GEOGRÁFICA DE CURSOS, VAGAS E EGRESSOS DE MEDICINA}

Os dados referentes a 2003 (Gráfico 2), do Instituto Nacional de Estudos e Pesquisas Educacionais Anísio Teixeira (Inep/ MEC), mostram que, do total das 125 escolas médicas consideradas no estudo, 48,0\% se concentram na Região Sudeste. Entretanto, verifica-se nessa região uma outra concentração, já que os estados de São Paulo, Rio de Janeiro e Minas Gerais ofertam, respectivamente, 20,0\% (25 cursos), 13,6\% (17 cursos) e $12,8 \%$ (16 cursos) do total dos cursos em funcionamento no País. A segunda maior oferta encontra-se na Região Sul, que participa com 19,2\% da oferta nacional (24 cursos), com quase a metade deles localizada no Rio Grande do Sul (11 cursos, equivalentes a $8,8 \%$ da oferta nacional); a outra metade se encontra nos estados do Paraná e Santa Catarina com, respectivamente, 7 e 6 cursos, correspondendo a 5,6\% e 4,8\% da oferta de cursos no País. Pode-se constatar que, além da oferta nos estados do Ceará (5 cursos), da Bahia e no Distrito Federal (4 cursos em cada), nas restantes 17 unidades federadas estão distribuídos 30 cursos ou 24,0\% do total da oferta nacional. $\mathrm{O}$ estado do Amapá é o único que não oferece o curso.

Em 1995 (Gráfico 1), das 85 escolas médicas existentes no País, 46 estavam concentradas na Região Sudeste, correspondendo a $54,1 \%$ da oferta dessas instituições de ensino no País, localizadas, primordialmente, nos estados de São Paulo (19 cursos), Rio de Janeiro (15 cursos) e Minas Gerais (10 cursos), seguidos do Rio Grande do Sul (10 cursos). Os restantes 31 cursos $(36,5 \%)$ estavam distribuídos por 23 outras unidades federadas. Ainda que se verifique maior participação de outros estados em 2003, se considerada a série histórica de nove anos, pode-se inferir que não houve uma política de desconcentração das instituições de ensino médico no País, o que contribuiu para manter a iniqüidade do acesso da população aos serviços de saúde. Como menciona Ceccim²:

O equilíbrio entre a distribuição das ofertas de formação e a distribuição da população, bem como a criação de mecanismos que favoreçam o acesso aos cursos para pessoas oriundas de regiões remotas precisa se tornar uma política pública ou institucional. (p.42)

A mesma dinâmica de concentração se observa em relação à oferta de vagas e de egressos. Em 1995, a Região Sudeste ofertava $57,7 \%$ do total das vagas nacionais e, em 2003, $55,9 \%$ desse total (Gráficos 3 e 4). Os egressos de 1995 e 2003 são igualmente originários da Região Sudeste (Gráficos 5 e 6), representando, respectivamente, 59,7\% e 60,9\% do total de egressos no País.

\section{GRÁFICO 1}

Cursos de graduação em Medicina, por regiões, segundo dependência administrativa. Brasil, 1995.

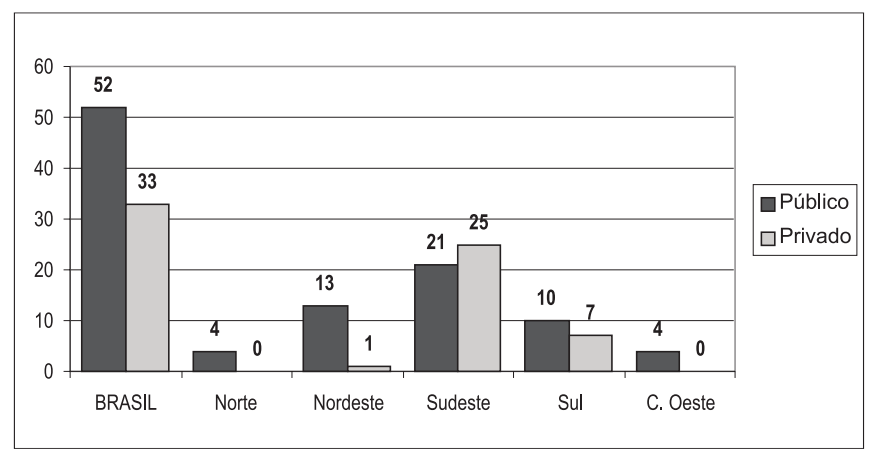

Fonte: Inep/MEC.

\section{GRÁFICO 2}

Cursos de graduação em Medicina, por regiões, segundo dependência administrativa. Brasil, 2003.

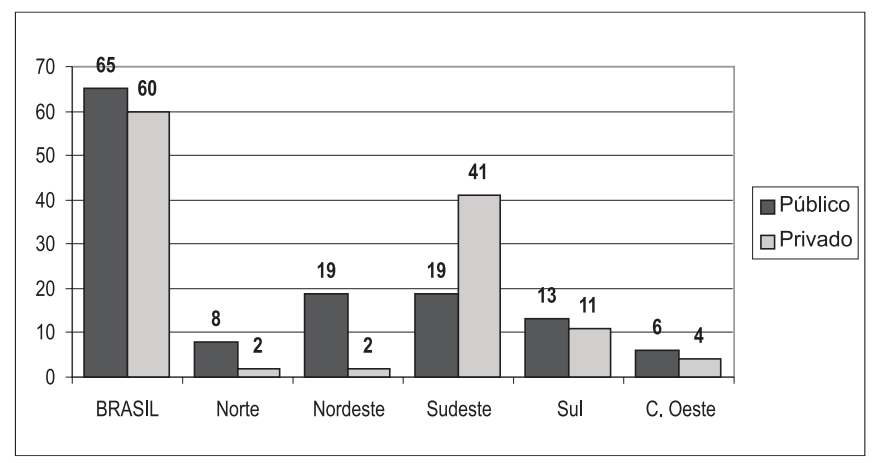

Fonte: Inep/MEC.

\section{GRÁFICO 3}

Vagas de graduação em Medicina, por regiões, segundo dependência administrativa. Brasil, 1995.

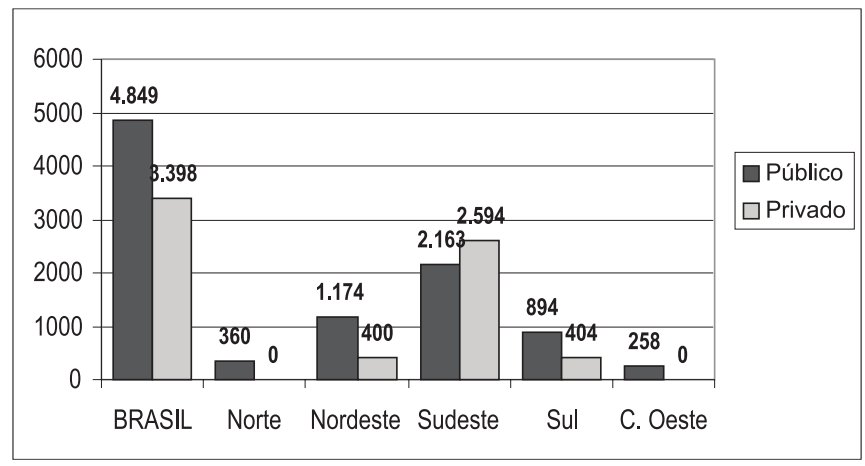

Fonte: Inep/MEC. 


\section{GRÁFICO 4}

Vagas de graduação em Medicina, por regiões, segundo dependência administrativa. Brasil, 2003.

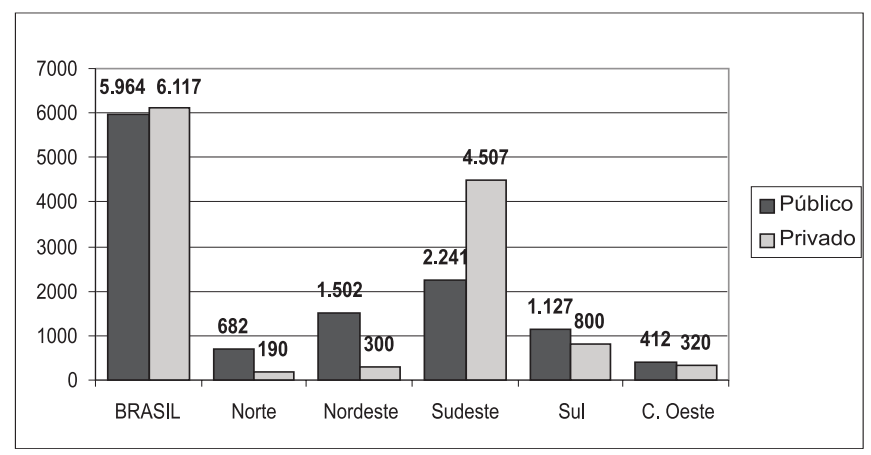

Fonte: Inep/MEC.

\section{GRÁFICO 5}

Egressos de graduação em Medicina, por regiões, segundo dependência administrativa. Brasil, 1995.

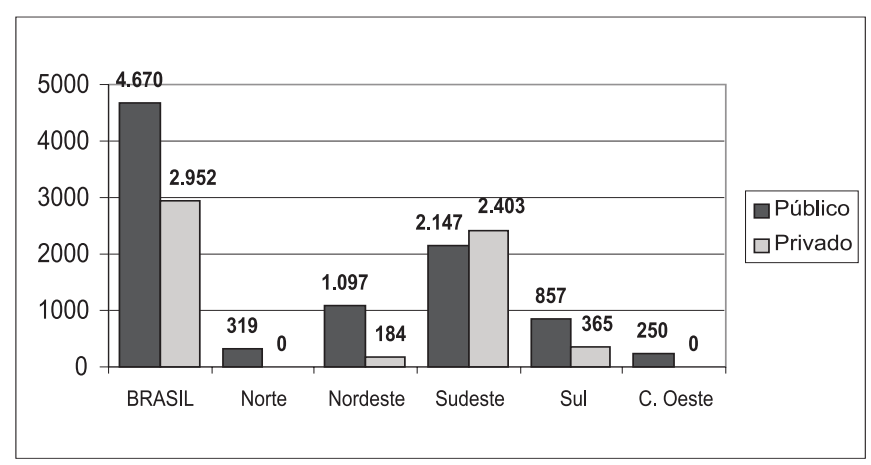

Fonte: Inep/MEC.

\section{GRÁFICO 6}

Egressos de graduação em Medicina, por regiões, segundo dependência administrativa. Brasil, 2003.

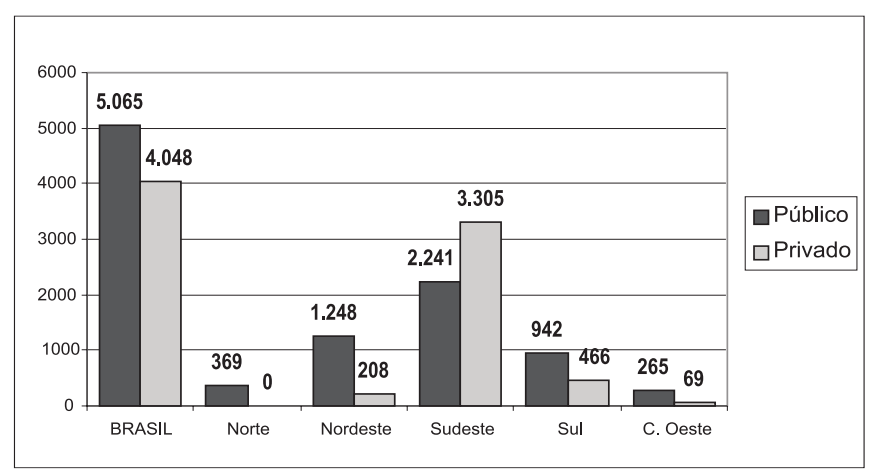

Fonte: Inep/MEC.

\section{Privatização do ensino de Medicina}

No que se refere à oferta de cursos por dependência administrativa, observa-se que no período analisado os cursos privados de Medicina apresentaram crescimento de $81,8 \%$, ou seja, de 33 escolas, a rede privada de ensino passou a possuir 60 escolas privadas. Já o crescimento das escolas de Medicina públicas, no mesmo período, foi de $25,0 \%$, de 52 para 65 escolas em 2003.

Atualmente, do total das escolas médicas no País (125), $52 \%$ são públicas e $48 \%$ são privadas, o que modifica substancialmente o cenário encontrado em 1995, em que 61,2\% eram públicas e $38,8 \%$ privadas (Gráficos 1 e 2). Esse crescimento se deu ao longo dos anos 1990 e 2000, principalmente após 1997, como conseqüência do advento e implementação da Lei de Diretrizes e Bases da Educação Nacional. Percebe-se que o crescimento da oferta total de cursos de Medicina no Brasil foi, basicamente, um movimento alicerçado nas instituições privadas de ensino.

O maior crescimento $(64,0 \%)$ é observado também na Região Sudeste, que de 25 passou a oferecer 41 escolas privadas, enquanto na esfera pública houve uma redução na oferta de unidades de ensino médico, de 21 para 19 escolas, no período de 1995 a 2003. Os Gráficos 1 e 2 mostram essa distribuição por regiões, no período.

O aumento dos cursos ocasionado pela privatização do ensino médico ocorreu de maneira substancial nas regiões Sudeste e Sul, particularmente nos estados de São Paulo, Rio de Janeiro, Minas Gerais e Rio Grande do Sul. Nas demais regiões, registre-se a criação de escolas de Medicina nos estados do Amazonas, Tocantins, Ceará, Mato Grosso, Mato Grosso do Sul e Distrito Federal. Em 2003, das 10 escolas localizadas na Região Norte, somente 2 são privadas; na Região Nordeste, das 21 escolas existentes, 2 são privadas.

Em relação à oferta de vagas em Medicina (Gráficos 3 e 4), observa-se a inversão da participação dos setores público e privado: em 1995, o setor privado respondia por $41,2 \%$ do total de vagas ofertadas; em 2003, essa oferta representava $50,6 \%$ (6.117 vagas privadas, do total de 12.081). Apenas a Região Sudeste ofertava 73,7\%, das vagas no País (4.507 vagas privadas, de um total de 6.117), que, somadas às da Região Sul, correspondem à maioria absoluta da oferta, ou $86,8 \%$ do total das vagas privadas no Brasil.

Apesar do grande crescimento das escolas e de vagas no setor privado, o setor público ainda responde pelo maior número de concluintes em Medicina (Gráficos 5 e 6). Em 1995, esse setor diplomou $61,3 \%$ dos concluintes (4.670 do total geral de 7.622) e, em 2003, 55,6\% (5.065 egressos do total de 9.113 egressos). A grande maioria dos concluintes é originária da 
Região Sudeste, seguida da Região Sul, sobressaindo os estados de São Paulo, Rio de Janeiro, Minas Gerais e Rio Grande do Sul. Em 2003, o quantitativo de egressos de escolas públicas apresenta-se mais elevado em todos os estados brasileiros, à exceção de São Paulo e Rio de Janeiro. Se comparada a oferta de vagas de 1997 (4.098) com o número de egressos das escolas privadas em 2003 (4.048), os números sugerem que a evasão também não é significativa nas escolas privadas.

\section{DINÂMICA DAS GRADUAÇÕES EM ENFERMAGEM}

\section{Crescimento da oferta em Enfermagem}

Em relação à graduação em Enfermagem, os dados da Tabela 2 revelam uma ampliação substancial dos cursos e vagas de 1995 a 2003 e conseqüente aumento no número de egressos.

No período, os cursos aumentaram de 108 para 334, um crescimento de $209,3 \%$, sendo que apenas nos últimos qua- tro anos o crescimento foi de 181 cursos (de 153 em 1999 para 334 em 2003), com o número de vagas ofertadas crescendo ainda mais (492,6\%), aumentando de 8.068 para 47.807 . Quanto ao número de egressos, observa-se uma expansão de 157,3\%, ou seja, de 4.373 em 1995 para 11.252 formados em 2003, com tendência de crescimento ainda maior, dado que a grande incidência de criação de cursos/vagas aconteceu nos anos 2000 .

Vários fatores representaram um contexto favorável ao grande crescimento dos cursos, das vagas e, em conseqüência, dos egressos da graduação em Enfermagem. Entre eles se destacam: o conjunto de normatizações efetivadas nos últimos anos, relacionadas, principalmente, à alocação de enfermeiros em serviços, à flexibilização do mercado de trabalho em geral e, em particular, do setor da saúde, às políticas públicas de saúde, que vêm ampliando substancialmente o mercado de trabalho setorial, e às políticas do setor de educação, que flexibilizaram seu sistema formador. 
TABELA 2

Cursos, vagas e egressos da graduação em Enfermagem por regiões, segundo unidades federadas. Brasil, 1995 e 2003

\begin{tabular}{|c|c|c|c|c|c|c|}
\hline \multirow{3}{*}{$\begin{array}{l}\text { Graduação } \\
\text { Região/UF }\end{array}$} & \multicolumn{6}{|c|}{ Enfermagem } \\
\hline & \multicolumn{2}{|c|}{ Cursos } & \multicolumn{2}{|c|}{ Vagas } & \multicolumn{2}{|c|}{ Egressos } \\
\hline & 1995 & 2003 & 1995 & 2003 & 1995 & 2003 \\
\hline Brasil & 108 & 334 & 8.068 & 47.807 & 4.373 & 11.252 \\
\hline Norte & 7 & 18 & 270 & 1676 & 280 & 454 \\
\hline Acre & 1 & 1 & 30 & 30 & 16 & 69 \\
\hline Amapá & 1 & 1 & 30 & 65 & 0 & 24 \\
\hline Amazonas & 1 & 5 & 40 & 691 & 37 & 108 \\
\hline Pará & 3 & 4 & 140 & 310 & 214 & 193 \\
\hline Rondônia & 1 & 3 & 30 & 230 & 13 & 27 \\
\hline Roraima & 0 & 0 & 0 & 0 & 0 & 0 \\
\hline Tocantins & 0 & 4 & 0 & 350 & 0 & 33 \\
\hline Nordeste & 22 & 47 & 1.615 & 5.239 & 1.023 & 1.925 \\
\hline Alagoas & 1 & 2 & 40 & 160 & 31 & 126 \\
\hline Bahia & 5 & 10 & 370 & 1.310 & 240 & 400 \\
\hline Ceará & 4 & 5 & 290 & 470 & 167 & 365 \\
\hline Maranhão & 2 & 5 & 140 & 1.332 & 77 & 112 \\
\hline Paraíba & 3 & 6 & 280 & 870 & 214 & 296 \\
\hline Pernambuco & 3 & 3 & 320 & 370 & 165 & 322 \\
\hline Piauí & 1 & 11 & 50 & 490 & 43 & 117 \\
\hline Rio Grande do Norte & 2 & 2 & 85 & 97 & 68 & 100 \\
\hline Sergipe & 1 & 3 & 40 & 140 & 18 & 87 \\
\hline Sudeste & 51 & 178 & 4.384 & 31.746 & 2.135 & 6.323 \\
\hline Espírito Santo & 1 & 8 & 60 & 1100 & 12 & 64 \\
\hline Minas Gerais & 8 & 47 & 580 & 4986 & 338 & 843 \\
\hline Rio de Janeiro & 12 & 34 & 1.104 & 8.080 & 743 & 1.208 \\
\hline São Paulo & 30 & 89 & 2.640 & 17.580 & 1.042 & 4.208 \\
\hline Sul & 23 & 71 & 1.485 & 6.844 & 782 & 1.994 \\
\hline Paraná & 7 & 29 & 345 & 3.069 & 268 & 800 \\
\hline Rio Grande do Sul & 12 & 25 & 880 & 2.643 & 395 & 863 \\
\hline Santa Catarina & 4 & 17 & 260 & 1.132 & 119 & 331 \\
\hline Centro-Oeste & 5 & 20 & 314 & 2.302 & 153 & 556 \\
\hline Distrito Federal & 1 & 6 & 56 & 772 & 30 & 127 \\
\hline Goiás & 2 & 6 & 168 & 900 & 74 & 228 \\
\hline Mato Grosso & 1 & 3 & 50 & 250 & 29 & 78 \\
\hline Mato Grosso do Sul & 1 & 5 & 40 & 380 & 20 & 123 \\
\hline
\end{tabular}

Fonte: Inep/MEC. 


\section{Distribuição geográfica da oferta de cursos, vagas e egressos de Enfermagem}

Em relação à Enfermagem, os dados do estudo mostram que, em 1995 (Gráfico 7), independentemente do tipo de instituição (pública ou privada) mantenedora dos cursos, a Região Norte participava com 6,5\% dos cursos, a Região Nordeste com 20,4\%, a Região Sudeste com $47,2 \%$, a Região Sul com $21,3 \%$ e a Região Centro-Oeste com 4,6\%. Observa-se, nos anos subseqüentes a 1995, mobilidade dos percentuais de cursos de Enfermagem, se examinados pelas regiões. Mas o aumento do número dos cursos não foi acompanhado de uma distribuição geográfica mais racional e lógica. Percentualmente, houve, inclusive, uma diminuição na participação das regiões Norte e Nordeste, que em 2003 responderam, respectivamente, por $5,4 \%$ e $14,1 \%$ do total de escolas existentes no País. Chama a atenção, ainda, a inexistência do curso em Roraima, tendo os profissionais que nele atuam se formado em outros estados. Cabe ressaltar, também, que o mais expressivo aumento da oferta do curso de Enfermagem ocorreu no Piauí, onde a quantidade de escolas, no período analisado, passou de uma para 11. Esta situação deve ser vista com reserva, pois os dados utilizados na elaboração deste artigo não permitem encontrar explicação plausível para o fenômeno, que, sem dúvida, merece ser objeto de análise em um próximo estudo.

Com relação às regiões Sudeste e, em escala menor, CentroOeste, o aumento do número de escolas nelas situadas fez com que a participação percentual na oferta de cursos no País se situasse, respectivamente, nos patamares de 53,3\% e 6,0\%. Dessa forma, em 2003, somente os estados de São Paulo, Minas Gerais e Rio de Janeiro, somados, representavam uma oferta de 50,9\% do total dos cursos de graduação em Enfermagem no Brasil (26,6\% em São Paulo, 14,1\% em Minas Gerais e 10,2\% no Rio de Janeiro). A segunda maior rede de escolas localiza-se na Região Sul, que representa $21,2 \%$ da oferta nacional, com os estados do Paraná contribuindo com 8,7\%, Rio Grande do Sul com 7,5\% e Santa Catarina com 5,0\% (Gráfico 8).

\section{GRÁFICO 7}

Cursos de graduação em Enfermagem, por regiões, segundo dependência administrativa. Brasil, 1995.

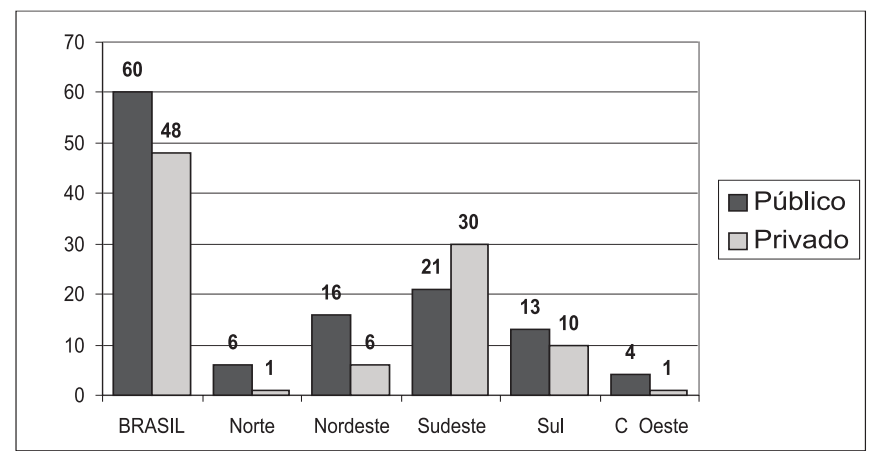

Fonte: Inep/MEC.

\section{GRÁFICO 8}

Cursos de graduação em Enfermagem, por regiões, segundo dependência administrativa. Brasil, 2003.

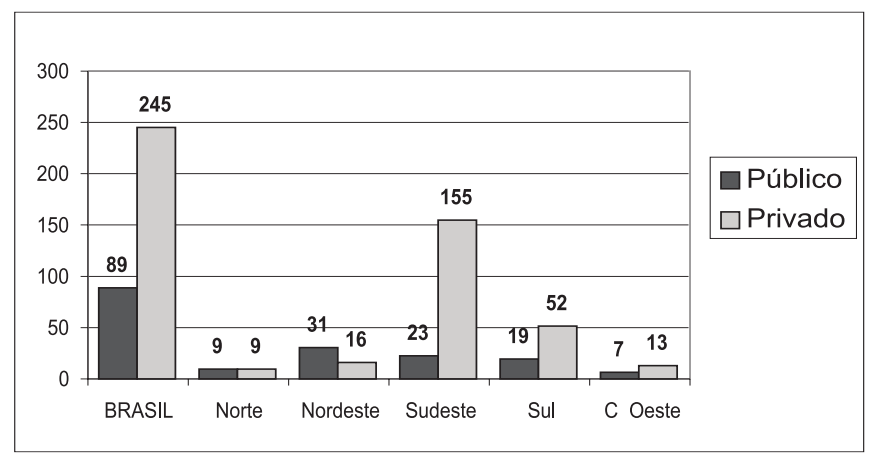

Fonte: Inep/MEC.

Na distribuição de vagas de graduação em Enfermagem, por regiões, observa-se maior concentração na Região Sudeste, sendo que em 2003 essa concentração atinge 66,4\% do total das vagas no País (31.746 vagas do total de 47.807) (Gráficos 9 e 10).

Assim, a Região Sudeste apresentou, no período considerado, um crescimento de vagas da ordem de 624,1\% (de 4.384, em 1995, para 31.746, em 2003). Somente os estados de São Paulo, Rio de Janeiro e Minas Gerais concentravam, em 2003, 64,1\% da oferta de vagas do País.

As regiões Sul e Nordeste representam as segunda e terceira maiores ofertas de vagas nacionais, participando, em 2003, respectivamente, com 14,3\% (6.844 vagas) e 11,0\% (5.239), com destaque para os estados do Paraná, Rio Grande do Sul, Maranhão, Bahia e Paraíba.

Essa mesma concentração geográfica pode ser observada em relação aos egressos, ou seja, em 2003, a Região Sudeste ofertava 56,2\% dos concluintes nacionais (6.323 de 11.252), particularmente os estados de São Paulo, Rio de Janeiro e Minas Gerais (Gráficos 11 e 12).

\section{GRÁFICO 9}

Vagas de graduação em Enfermagem, por regiões, segundo dependência administrativa. Brasil, 1995.

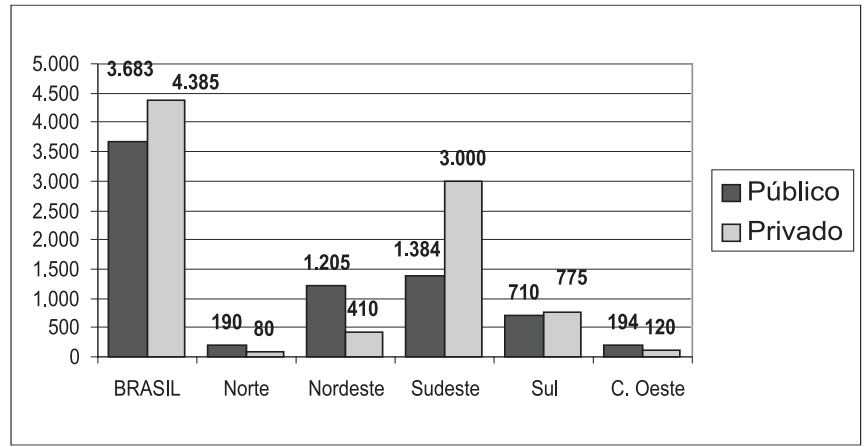

Fonte: Inep/MEC. 


\section{GRÁFICO 10}

Vagas de graduação em Enfermagem, por regiões, segundo dependência administrativa. Brasil, 2003.

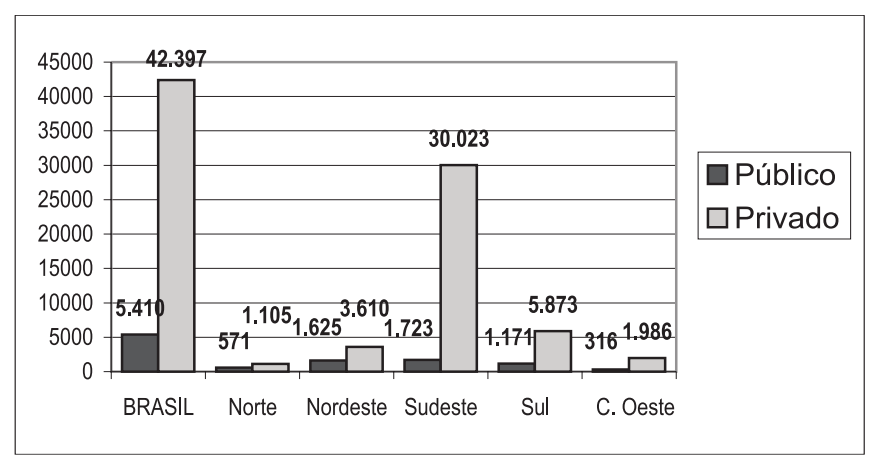

Fonte: Inep/MEC.

As regiões Sul e Nordeste também constituem a segunda maior oferta de egressos, respectivamente $17,7 \%$ (1.994) e 17,1\% (1.925), sobressaindo os estados do Rio Grande do Sul, Paraná e Bahia, Ceará, Pernambuco e Paraíba (Gráfico 12).

\section{GRÁFICO 11}

Egressos de graduação em Enfermagem, por regiões, segundo dependência administrativa. Brasil, 1995.

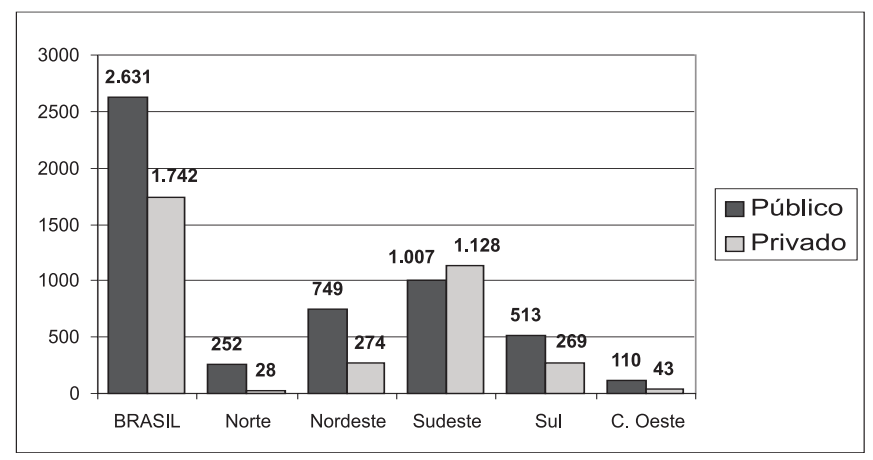

Fonte: Inep/MEC.

\section{GRÁFICO 12}

Egressos de graduação em Enfermagem, por regiões, segundo dependência administrativa. Brasil, 2003.

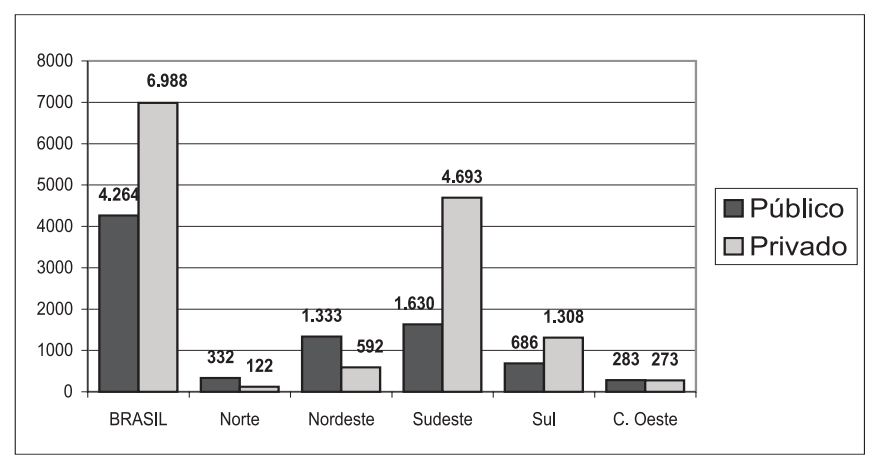

Fonte: Inep/MEC.

\section{Privatização do ensino de Enfermagem}

De maneira exemplar, a Enfermagem reflete, em 2003, o crescimento da privatização de seu ensino graduado. Assim, de 1995 a 2003 (Gráficos 7 e 8), em termos percentuais, o crescimento dos cursos privados de Enfermagem foi de 125,0\% (de 48 para 108 cursos), e o dos cursos públicos foi de $48,3 \%$ (de 60 para 75 cursos). Vale mencionar que tal crescimento é observado, primordialmente, a partir de 1997, refletindo a flexibilização e a autonomia das instituições de ensino, resultantes da aplicação dos dispositivos da mais recente Lei de Diretrizes e Bases da Educação Nacional ${ }^{3}$.

Dessa forma, em 2003 os cursos superiores privados de Enfermagem representavam $73,4 \%$, e os públicos, $26,6 \%$ do total de cursos instalados no País. Destaque-se que, salvo a Região Norte, em que a oferta de cursos privados e públicos se equivale, nas demais regiões o grande crescimento dos cursos se deu nas instituições privadas. No caso da Enfermagem, a concentração da oferta privada também foi verificada na Região Sudeste $(63,2 \%)$, principalmente nos estados de São Paulo (com 31,8\% do total de cursos privados do País), Minas Gerais (com 16,3\%) e Rio de Janeiro (com 12,2\%).

Como se observa nos Gráficos 9 e 10, o crescimento das vagas privadas de Enfermagem, no País, foi da ordem de 866,9\% (de 4.385 para 42.397) entre 1995 e 2003, sendo na Região Norte de $1.281,3 \%$ (de 80 para 1.105); na Nordeste, de 780,5\% (410 para 3.610); na Sudeste, de 900,8\% (3.000 para 30.023); na Sul, de 632,0\% (de 775 para 5.673); e na Centro-Oeste, de 1.555,0\% (120 para 1.986). Por sua vez, o crescimento das vagas públicas, no Brasil, foi de apenas $46,9 \%$ (de 3.683 para 5.410 vagas), e, embora em números absolutos seja menor a oferta de vagas na Região Norte, esse crescimento foi de 200,5\% (de 190 para 571 vagas). Na Região Nordeste, de 35,2\% (1.205 para 1.629), na Sudeste, de 24,5\% (1.384 para 1.723), na Sul, de 64,9\% (710 para 1.171) e na Centro-Oeste, de 62,9\% (194 para 316 vagas).

Em relação aos egressos de Enfermagem, se, em 1995, 60,2\% eram originários de cursos públicos, esta situação se inverte em 2003 , com $62,1 \%$ concluintes provenientes de instituições privadas de ensino, com tendência de crescimento ainda maior, considerando o grande aumento de cursos privados nos anos 2000. Assim, no período analisado, a oferta de egressos das instituições privadas no País passa de 1.742 para 6.988, enquanto nas instituições públicas de 2.631 para 4.264, o que retrata o incisivo processo de privatização da graduação em Enfermagem no País.

\section{COMENTÁRIOS}

A análise das graduações em Medicina e Enfermagem no período de 1995 a 2003 permite dizer que ambas apresentam 
como características crescimento acelerado da oferta de cursos e vagas e, em conseqüência, de egressos, forte concentração geográfica na Região Sudeste - primordialmente nos estados de São Paulo e Rio de Janeiro - e crescente privatização do sistema de ensino.

Entre as razões possíveis desse quadro, cumpre mencionar as mudanças provocadas pela Lei de Diretrizes e Bases da Educação $\mathrm{Nacional}^{3}$, que favoreceram a criação de cursos e a privatização do ensino, em virtude da maior autonomia concedida às instituições de ensino superior. A intensa abertura de cursos, ocorrida a partir de meados da década de 1990, promoveu uma expansão crescente das faculdades e universidades privadas, resultando em que, do total de vagas ofertadas, o setor público detém, hoje, $30 \%$, e o setor privado, $70 \%$, a mesma correspondência observada nas graduações da área de saúde.

Frente a esse contexto, é preciso reafirmar que o ensino é um bem público e que o Estado não deve nem pode abrir mão de seu papel de regular, orientar e ordenar a abertura de novos cursos, além de instituir um processo permanente de avaliação da qualidade do ensino ministrado. Essa é uma antiga e permanente preocupação do Conselho Nacional de Saúde, que desenvolve esforços sistemáticos para que os ministérios da Saúde e da Educação atuem de maneira conjunta e articulada, na perspectiva de construir um marco regulatório que oriente as autorizações dos cursos superiores*, com o objetivo de defender e expandir o ensino público e organizar o ensino privado, garantindo a qualidade da formação. O Conselho atua ainda, incisivamente, para que se defina, com maior clareza, o papel do Estado como regulador no processo da regionalização, ampliação da rede pública de ensino e implementação de propostas pedagógicas inovadoras no âmbito da saúde ${ }^{4}$. Tal movimento aponta para a construção de mecanismos e instrumentos que possam alterar as tendências observadas e que caracterizam o sistema de ensino no País como desordenado, desigual e privatizado.

Por fim, um fato revelador dessa preocupação em busca de mecanismos de regulação, aproximando critérios de qualidade e de regionalização, diz respeito à iniciativa do Ministério da Saúde, por intermédio da Secretaria de Gestão do Trabalho e da Educação na Saúde, que assume o papel "definido na legislação, de gestor federal do Sistema Único de Saúde no que diz respeito à formulação das políticas orientadoras da formação, desenvolvimento, distribuição, regulação e gestão

\footnotetext{
* Os critérios de regulação da abertura e reconhecimento de novos cursos da área de saúde estão estabelecidos na Resolução no 350, de 9 de junho de 2005, do Conselho Nacional de Saúde, a qual considera as necessidades sociais do curso, a coerência do projeto político com as necessidades sociais e a relevância social do curso.
}

dos trabalhadores de saúde no Brasil" 5,6, em relação aos Pólos de Educação Permanente em Saúde ${ }^{7}$. Estes representam um espaço de integração interinstitucional para a proposição de alternativas de integração entre universidade e serviço, visando ordenar a formação e o desenvolvimento dos trabalhadores da saúde.

\section{REFERÊNCIAS}

1. Brasil.Ministério da Saúde. Conselho Nacional de Saúde. $12^{\circ}$ Conferência Nacional de Saúde Sergio Arouca. Relatório Final. Brasília: Ministério da Saúde; 2004. p. 116.

2. Ceccim, RB. Por que uma Lei Orgânica da Educação Superior precisa contemplar de maneira especial e dedicada a articulação com o setor da saúde. Olho Mágico 2005;12(1): 35-45.

3. Brasil. Ministério da Educação. Lei nº 9.394, de 20/12/96. Estabelece as diretrizes e bases da educação nacional. Brasília: MEC; 1996.

4. Brasil. Ministério da Educação e Ministério da Saúde. Discussão sobre a política de abertura de cursos de graduação da área da saúde no Brasil, necessidade de regulação pelo Estado e correspondência ao interesse público. Nota técnica Brasília: Ministério da Saúde; 2004. [mimeo].

5. Brasil. Ministério da Educação. Instituto Nacional de Estudos e Pesquisas Educacionais Anísio Teixeira (INEP). Censo da Educação Superior: Brasília:MEC; 2003.

6. Brasil. Ministério da Saúde. Política de Educação e desenvolvimento para o SUS. Caminhos para a educação permanente em saúde. Pólos de Educação permanente em saúde. Secretaria de Gestão do Trabalho e da Educação na Saúde. Departamento de Gestão e da Educação na Saúde. Brasília: Ministério da Saúde; 2003.

7. Ceccim, RB. Educação Permanente em Saúde: descentralização e disseminação de capacidade pedagógica na saúde. Rev C S Col 2005: 10(4):975-986.

\section{Conflito de Interesse}

Declarou não haver.

\section{Endereço para correspondência}

Antenor Amâncio Filho e-mail: amancio@ensp.fiocruz.br

Ana Luiza Stiebler Vieira e-mail: stiebler@ensp.fiocruz.br

Ana Cláudia Pinheiro Garcia e-mail: ana.garcia@ensp.fiocruz.br 